\title{
Labyrinthe
}

$40 \mid 2013$

Comme les abeilles

\section{Le « communisme monarchique » des abeilles chez Virgile}

\section{Renaud Pasquier}

\section{(2) OpenEdition \\ 1 Journals}

Édition électronique

URL : http://journals.openedition.org/labyrinthe/4327

DOI : $10.4000 /$ labyrinthe.4327

ISSN : 1950-6031

Éditeur

Hermann

Édition imprimée

Date de publication : 1 mars 2013

Pagination : 119-120

ISBN : 9782705688400

\section{Référence électronique}

Renaud Pasquier, « Le « communisme monarchique » des abeilles chez Virgile », Labyrinthe [En ligne], 40 | 2013, mis en ligne le 01 mars 2015, consulté le 01 mai 2019. URL : http://

journals.openedition.org/labyrinthe/4327 ; DOI : 10.4000/labyrinthe.4327

Propriété intellectuelle 


\title{
Le « communisme monarchique » des abeilles chez Virgile
}

\author{
Renaud PASQUIER
}

La quatrième Géorgique n'est pas le simple entrelacs d'une didactique (plus morale et patriotique que réellement technique) et d'une esthétique délicate et raffinée. Un troisième fil complique et parachève la tresse : la description ethnographique de la vie des abeilles. Il n'est plus question de conseiller l'apprenti apiculteur; Virgile change de registre, et rend compte scrupuleusement de l'organisation sociale de la ruche. On a pu parler à ce propos de « communiste monarchique ${ }^{1}$ ": les abeilles sont représentées comme un peuple industrieux, où les tâches sont rationnellement distribuées sans principe hiérarchique, sans qu'un individu prenne un instant le pas sur la collectivité, sinon le roi, âme de la ruche, auquel tous sont absolument dévoués; qu'il meure, et voilà ses sujets perdus et incapables de maintenir l'ordre et la paix. Difficile de ne pas songer à une analogie avec la situation romaine, et Auguste en souverain abeille garantissant paix, unité, prospérité, après les guerres civiles qu'évoque la description des combats entre deux essaims placés sous le signe de la discordia. L'ambition propagandiste se vérifierait donc, la place conclusive réservée aux abeilles comme emblème politique en serait l'attestation.

Si la lecture politique est séduisante, car historiquement cohérente, elle demeure pourtant insatisfaisante: d'abord parce que ce serait faire bon marché de l'humour virgilien, le poète s'amusant visiblement à esquisser une parodie burlesque d'épopée (exercice préparatoire, peut-être, à la véritable épopée que sera l'Enéide, comme bien des commentateurs l'ont suggéré), ce qui relativise le sérieux et la gravité du discours politique où les abeilles seraient moins humanisées que les hommes animalisés, et leurs vaines guerres ridiculisées; ensuite parce que le régime politique

1. Cf. entre autres Jean Bayet, Mélanges de littérature latine, Rome, Edizioni di storia e letteratura, 1967, p. 294. 


\section{Labyrinthe, $n^{\circ} 40$}

de la ruche décrit par Virgile est moins proche du Principat augustéen que des monarchies orientales, d'ailleurs citées en comparaison pour célébrer l'amour fidèle des abeilles pour leur roi (ni les Parthes, ni les Mèdes, ni les Egyptiens, ni les Lydiens ne font montre d'une telle loyauté envers leur souverain, selon les vers 210-211), ce terme même de « roi » étant impossible sous un régime qui se proclame républicain. On pourrait alors imaginer que Virgile ne cherche pas à représenter la réalité politique romaine, mais à proposer une modèle alternatif, une sorte d'utopie, manière d'indiquer à Octave l'idéal à viser. Cette hypothèse ne tient pas plus, pour deux raisons, deux éléments absents respectivement dans le texte de Virgile et dans la situation politique contemporaine qui entravent le fonctionnement de l'analogie. L'apiculteur est le premier, sans équivalent dans la réalité politique romaine: doit-on l'assimiler à Auguste ? Impossible, car ce dernier serait déjà l'analogue du roi des abeilles, et parce que l'apiculteur appartient à une espèce différente, véritable deux ex machina qui assure la survie de la communauté (et l'absence de cette instance à Rome signifierait alors le pessimisme politique du poète). Le second est plus subtil, et plus profond: dans la société des abeilles, il n'y a pas de poète. Cela paraîtra évidemment peu surprenant, sauf si l'on se souvient que l'abeille est fort souvent emblème d'éloquence ou de poésie: or cette métaphore classique, et très attendue chez Virgile, brille ici par son absence.

Si la politique est bien présente, sous les formes de l'allusion, la spéculation, ou l'exercice discrètement parodique, elle n'épuise pas le sens attribué au motif des abeilles et n'indique pas dès lors la signification ultime des Géorgiques. C'est en se penchant sur le mythe qui conclut la quatrième Géorgique, et le poème, que l'on pourra tenter une interprétation plus satisfaisante. 